\title{
Er-doped Tellurite glasses for planar waveguide power amplifier with extended gain bandwidth
}

\author{
J. I. Mackenzie ${ }^{1 *}$, G. S. Murugan ${ }^{1}$, T. Suzuki ${ }^{2}$, Y. Ohishi ${ }^{2}$, A.W. Yu ${ }^{3}$ and J.B. Abshire ${ }^{4}$ \\ ${ }^{1}$ Optoelectronics Research Centre, University of Southampton, Southampton SO17 1BJ, U.K. \\ ${ }^{2}$ Research Center for Advanced Photon Technology, Toyota Technological Institute, 2-12-1 Hisakata, \\ Tempaku, Nagoya 468-8511, Japan \\ ${ }^{3}$ Laser \& Electro-Optics Branch, NASA Goddard Space Flight Center, Greenbelt, MD 20771, U.S.A \\ ${ }^{4}$ Solar System Exploration Division, NASA Goddard Space Flight Center, Greenbelt, MD 20771, \\ U.S.A
}

Keywords: Optical Materials, Tellurite, Erbium, Erbium/Ytterbium, Laser amplifier, $\mathrm{CO}_{2}$

\begin{abstract}
:
Tellurite glass compositions doped with erbium and erbium/ytterbium optimised to support extended gain bandwidth with significant amplification have been fabricated, and their thermal, optical absorption, excitation and luminescence properties investigated. Each rare-earth dopant concentration was set at $1 \times 10^{20} \mathrm{~cm}^{-3}$. Broad emission cross-section bandwidths up to 50nm FWHM were observed, with fluorescence lifetimes of $\sim 3 \mathrm{~ms}$. Collinear pump probe measurements on $\sim 4 \mathrm{~mm}$ thick bulk samples revealed peak gains of up to $2.1 \mathrm{~dB} / \mathrm{cm}$ at a wavelength of $1535 \mathrm{~nm}$ in the co-doped material, with an incident pump intensity of only $\mathrm{I}_{\mathrm{inc}} \sim 8 \mathrm{kWcm}^{-2}$ at a wavelength of $974 \mathrm{~nm}$. At equivalent absorbed pump powers between co-doped and single doped materials the relative gain was $1.25 \mathrm{~dB} / \mathrm{cm}\left(\mathrm{I}_{\text {inc }} \sim 4 \mathrm{kWcm}^{-2}\right)$ and $0.9 \mathrm{~dB} / \mathrm{cm}\left(\mathrm{I}_{\text {inc }} \sim 8 \mathrm{kWcm}\right)$ respectively, demonstrating efficient energy transfer from the ytterbium to erbium ions. Excited state absorption at longer wavelengths was observed and characterised and its implication on realising sufficient gain in the wavelength band of interest is discussed.
\end{abstract}

\section{INTRODUCTION}

Studies of carbon dioxide $\left(\mathrm{CO}_{2}\right)$ concentration in ice-cores has raised concerns that our planet currently has the highest level of atmospheric $\mathrm{CO}_{2}$ than at any time in the past $0.4 \mathrm{M}$ years. As such there is a strong drive to develop the appropriate tools to gather sufficient data to better understand the nature and processes of $\mathrm{CO}_{2}$ sinks on a global scale. This information will enable more informative predictive models for future atmospheric compositions and climate dynamics. The approach being targeted at NASA's Goddard Space Flight Centre is to develop an efficient high-power tuneable MOPA source seeded by pulsed narrow-linewidth diode-lasers, wavelength swept through absorption peaks of $\mathrm{CO}_{2}$ around $1575 \mathrm{~nm}$. This laser system will then be coupled to a dual channel laser absorption spectrometer (i.e. DIAL lidar used in altimeter mode) and deployed to make accurate measurements of the abundance of tropospheric $\mathrm{CO}_{2}$ from space, continuously measuring at all times of the night and day throughout the year [1].

In this paper we detail our investigation of erbium-doped tellurite glasses with and without ytterbium co-doping that can provide gain at wavelengths beyond the traditional telecommunications $\mathrm{C}$-band and overlap the $\mathrm{CO}_{2}$ absorption line around $1575 \mathrm{~nm}$. These glasses are well suited to the planar waveguide geometry and different fabrication techniques [2, 3], which can provide significantly larger active mode-areas than fibre based amplifiers, thus mitigating non-linear processes (i.e. Stimulated Brillouin Scattering and Stimulated Raman Scattering) limiting the achievable peak power, which are exacerbated by the narrow linewidth output requirement of gas spectroscopy. Moreover due to the higher emission cross section offered by tellurite glasses with respect to silicates $[4,5]$, there is the potential to make a more compact gain-module for the power amplifier stage in a MOPA system, like the one being developed for the ASCENDS space mission [1]. To date in our samples we have measured gains of $2 \mathrm{dBcm}^{-1}$ at the $1535 \mathrm{~nm}$ peak and $0.7 \mathrm{dBcm}^{-1}$ around $1575 \mathrm{~nm}$ the key wavelength of interest.

*jim@orc.soton.ac.uk; phone +44 238059 4521, fax +44 238059 3142, www.orc.soton.ac.uk 


\section{METHODOLOGY}

\subsection{Materials selection}

Er-doped silica based glasses show only a relatively narrow emission band (FWHM $\approx 30 \mathrm{~nm}$ ) peaking around $1530 \mathrm{~nm}$ and therefore are not suitable for the application of interest. Er-doped tellurite glasses are primarily of interest because of their broad and strong emission band (up to FWHM $\approx 70 \mathrm{~nm}$ ) with considerable emission around the $1575 \mathrm{~nm}$ wavelength band. However, the low phonon energy $\left(<800 \mathrm{~cm}^{-1}\right)$ of tellurite glasses does not facilitate the fast and efficient non-radiative decay (due to multi-phonon relaxation) between the $\mathrm{Er}^{3+}$ ions ${ }^{4} \mathrm{I}_{11 / 2}$ and ${ }^{4} \mathrm{I}_{13 / 2}$ energy states, especially important in the $\mathrm{Yb} / \mathrm{Er}$ codoped system and $980 \mathrm{~nm}$ pumping configurations, where it is necessary to ensure back-transfer of energy to the $\mathrm{Yb}^{3+}$ ions is minimised. Borate based glasses have more energetic phonons reaching up to about $1400 \mathrm{~cm}^{-1}$, yet their Er-doped stimulated emission characteristics are generally poor. However, it has been reported that a small amount of $\mathrm{B}_{2} \mathrm{O}_{3}$ in tellurite glass helps to promote the non-radiative decay from ${ }^{4} \mathrm{I}_{11 / 2}$ to ${ }^{4} \mathrm{I}_{13 / 2}$, while large amounts of $\mathrm{B}_{2} \mathrm{O}_{3}(>8$ mol\%) are observed to decrease the lifetime and quantum efficiency of the radiative transition from ${ }^{4} \mathrm{I}_{13 / 2}$ to ${ }^{4} \mathrm{I}_{15 / 2}$ [6]. On the other hand the addition of $\mathrm{GeO}_{2}$ is reported to increase the life time of the ${ }^{4} \mathrm{I}_{13 / 2}$ state [7]. Nonetheless, we cannot use the glass compositions reported in [7] due to their poor thermal properties, mainly attributed to the presence of $\mathrm{K}_{2} \mathrm{O}$ and partly due to the higher amount of $\mathrm{ZnO}$. Instead alkaline earth oxides (in particular $\mathrm{MgO}$ ) as glass modifiers in tellurite glass have been reported to have higher and broader emission cross-section [8]. Therefore, we have chosen to investigate the following glass compositions, (A) $72.5 \mathrm{TeO}_{2}-10 \mathrm{ZnO}-10 \mathrm{MgO}-7.5 \mathrm{~B}_{2} \mathrm{O}_{3}$, and (B) $65 \mathrm{TeO}_{2}-10 \mathrm{ZnO}-10 \mathrm{MgO}-7.5 \mathrm{~B}_{2} \mathrm{O}_{3}-7.5 \mathrm{GeO}_{2}$ mol\%, which were either (1) undoped, (2) singly doped with $\mathrm{Yb}^{3+}$, or (3) $\mathrm{Er}^{3+}$, and finally (4) co-doped with $\mathrm{Er}^{3+}$ and $\mathrm{Yb}^{3+}$. For each sample the rare earth ion(s) dopant concentration was set to $1.0 \times 10^{20}$ ions $/ \mathrm{cm}^{3}$.

\subsection{Preparation of samples}

The glass samples were obtained by a conventional melt quenching method. The starting materials were of $99.99 \%$ purity. About $20 \mathrm{~g}$ batches of starting materials were fully melted in a platinum crucible in an electric furnace at $800{ }^{\circ} \mathrm{C}$ for $20 \mathrm{~min}$. The furnace was purged with dry $\mathrm{O}_{2}$ and $\mathrm{N}_{2}$ at a flow rate of $3 \mathrm{~L} / \mathrm{min}$ to prevent hydroxyl impurity contamination. The melts were poured onto a preheated steel plate, and then were annealed at temperatures closer to the glass transition temperatures for $10 \mathrm{~h}$ in an electric furnace. The obtained glasses were cut into specimens of approximately $20 \mathrm{~mm} \times 20 \mathrm{~mm} \times 4 \mathrm{~mm}$ and polished carefully to meet the requirement for optical measurements.

\subsection{Thermal analysis}

Thermal analyses were carried out to confirm the glassy nature and to find the thermal stability of the samples. Powdered samples of about $45 \mathrm{mg}$ weight were put in a platinum pan and measured using a differential scanning calorimeter (Rigaku, ThermoPlus DSC 8270) at a heating rate of $10{ }^{\circ} \mathrm{C} / \mathrm{min}$ from room temperature to $800{ }^{\circ} \mathrm{C}$. The measurements were performed in a nitrogen atmosphere. The glass transition temperature $\left(\mathrm{T}_{\mathrm{g}}\right)$ and the crystallization temperature $\left(\mathrm{T}_{\mathrm{x}}\right)$ were obtained from the tangent intersections of the endothermic and exothermic peaks of the differential scanning calorimetry (DSC) curves, respectively.

\subsection{Optical measurements}

The refractive indices of the samples were measured with a prism coupler system (Metricon, Model 2010) at wavelengths of $632.8,974,1320$, and $1544 \mathrm{~nm}$. The measured refractive indices were fitted to Sellmeier's dispersion formula in the following form:

$$
n(\lambda)^{2}=1+\frac{A \lambda^{2}}{\lambda^{2}-C}+\frac{B \lambda^{2}}{\lambda^{2}-D}
$$

where $\lambda$ is the wavelength in units of $(\mu \mathrm{m})$ and the coefficients $A, B, C$, and D are constants. The values of the parameters $\mathrm{A}, \mathrm{B}, \mathrm{C}$, and D obtained for the various glasses are listed in Table 1.

The sample's optical transmission were measured with a UV-VIS-NIR double beam spectrophotometer (Cary 500) in the spectral range of $300 \sim 3300 \mathrm{~nm}$, in addition higher resolution scans were made of the absorption bands around the $980 \mathrm{~nm}$ and $1500 \mathrm{~nm}$ wavelengths, i.e. the pump and emission bands of interest.

In the emission decay measurements, a diode laser source with a wavelength of $973 \mathrm{~nm}$ was used as the excitation source for the doped samples. The emission from the samples was measured with a monochromator equipped with a photomultiplier tube as a detector. The emission signal was monitored using a lock-in amplifier and a digital oscilloscope 
was used to record the output signal from the detector as it evolved with time. Emission lifetimes were obtained from the first e-folding time of the emission decay curve.

\subsection{Raman measurements}

The Raman spectra were measured with a Renishaw Raman spectrometer in the spectral range $100-2000 \mathrm{~cm}^{-1}$. The glass sample was excited with a frequency doubled Nd-YAG laser at $532 \mathrm{~nm}$. The spectrum was observed in the back scattered mode and the digital intensity data were recorded at intervals of $1 \mathrm{~cm}^{-1}$.

\subsection{Gain measurements}

Pump-probe gain measurements were made on the bulk samples to determine the potential of each glass composition, particularly in the range of interest around $1575 \mathrm{~nm}$. We used a $974 \mathrm{~nm}$ fibre-coupled diode pump source (Oclaro LC96UF74-20R), in pulsed-mode driven by an arbitrary waveform function generator (Tektronix AFG 3102) to produce $10 \mathrm{~ms}$ pulses at a $2 \%$ duty cycle, thus avoiding detrimental thermo-optical effects in the un-mounted samples. The output from the fibre-couple diode was re-imaged into the sample to a beam diameter of $130 \mu \mathrm{m}$ and the pump power altered to provide incident intensities ranging from $2 \mathrm{kWcm}^{-2}$ to $8 \mathrm{kWcm}^{-2}$. A CW tuneable diode source (Tunics Plus CL/WB) was then used as the probe, where the single mode fibre output was also reimaged into the sample, in the same direction and collinear with the pump, and matched in beam size, i.e. $130 \mu \mathrm{m}$ diameter. The wavelength of the probe could be set between 1500-1600 nm with power levels up to $3 \mathrm{~mW}$. The probe and residual pump beams were separated using a dichroic mirror that passed the shorter wavelength, and the power change monitored for both pump and probe during the excitation pulse. For the probe beam a large area Germanium detector (Thorlabs Model: SM1PD5B), mounted behind a 3 mm uncoated Silicon filter, was used, while for the pump the detector was a custom Silicon large area photodiode covered by a neutral density filter (OD 2). Both photodiode output waveforms associated with the $10 \mathrm{~ms}$ pump pulse were recorded for 4 different pump intensities on a digital oscilloscope (Agilent MSO6104) and the measurement repeated at a range of probe wavelengths. The net gain for each sample was then calculated for the various pump intensities with respect to the unpumped probe power prior to the start of the excitation pulse.

\section{RESULTS AND DISCUSSION}

\subsection{Thermal measurements}

The glass transition temperature $\left(T_{g}\right)$, crystallization temperature $\left(T_{x}\right)$ and thermal stability $(\Delta T)$ for the singly and co-doped samples studied are listed in Table 1 . The $T_{g}$ and $T_{x}$ of the glasses in both series A and $B$ were not very much affected by the doping as seen in Table 1. The addition of $\mathrm{GeO}_{2}$ to the glass composition shifted both the $\mathrm{T}_{\mathrm{g}}$ and $\mathrm{T}_{\mathrm{x}}$ to higher temperatures and also the thermal stability of the $\mathrm{GeO}_{2}$ containing glasses were better than the glasses without it (series A).

Table 1: Glass transition temperature $\left(\mathrm{T}_{\mathrm{g}}\right)$, crystallization temperature $\left(\mathrm{T}_{\mathrm{x}}\right)$ and thermal stability $(\Delta \mathrm{T})$ for the singly and codoped glasses.

\subsection{Optical measurements}

\begin{tabular}{cccc}
\hline \hline Sample & $\mathrm{T}_{\mathrm{g}}\left({ }^{\circ} \mathrm{C}\right)$ & $\mathrm{T}_{\mathrm{x}}\left({ }^{\circ} \mathrm{C}\right)$ & $\Delta \mathrm{T}\left({ }^{\circ} \mathrm{C}\right)$ \\
\hline $\mathrm{A} 3$ & 338 & 411 & 73 \\
$\mathrm{~A} 4$ & 339 & 411 & 72 \\
$\mathrm{~B} 3$ & 364 & 459 & 95 \\
$\mathrm{~B} 4$ & 367 & 463 & 96 \\
\hline \hline
\end{tabular}

Around $1550 \mathrm{~nm}$ the refractive index of the A-series samples was $\mathrm{n}_{\mathrm{A}} \sim 1.98$, while for the B-series it was $\mathrm{n}_{\mathrm{B}} \sim 1.94$. The dispersion formulae coefficients are listed in Table 2 for the Er-doped samples, covering the wavelength range of $600-$ $1600 \mathrm{~nm}$. It is observed that the magnitude of the refractive index is primarily driven by the percentage content of $\mathrm{TeO}_{2}$.

Table 2: Sellmeier coefficients for the singly and co-doped samples studied.

\begin{tabular}{ccccc}
\hline \hline Sample & A & B & C & D \\
\hline A3 & 2.938265931 & 3.136647099 & 0.028717622 & 354.3829418 \\
A4 & 2.929740676 & 3.04378365 & 0.028955249 & 365.4515142 \\
B3 & 2.746242763 & 3.35962262 & 0.025997219 & 312.450031 \\
B4 & 2.748505129 & 3.521351781 & 0.025325754 & 292.1057229 \\
\hline \hline
\end{tabular}


Results of the transmission measurements of each of the samples around the pump and signal wavelengths are shown in Fig. 1. It is apparent that the inclusion of $\mathrm{GeO}_{2}$ into the matrix (B-series glasses) did in fact reduce the bandwidth and magnitude of the absorption cross sections for the erbium and ytterbium ions, in addition to slightly reducing the emission cross section, as presented in Table 3 and Fig. 2. However, in the samples investigated here, unlike the previous report [7], there was no improvement in the lifetime of the ${ }^{4} \mathrm{I}_{13 / 2}$ state in the exchange of Te with Ge. Instead it appears that the lifetime of the ${ }^{4} \mathrm{I}_{13 / 2}$ level is dominated by non-radiative decay due to the glass' higher phonon energy spectrum introduced through the $\mathrm{B}_{2} \mathrm{O}_{3}$ component, for which the maximum phonon energy is a quarter of the energy gap to the ground state [6]. It should be noted that the Er-doping level of $1 \times 10^{20} \mathrm{~cm}^{-3}$ is relatively low and cross-relaxation energy transfer rates are typically small at this level [9].

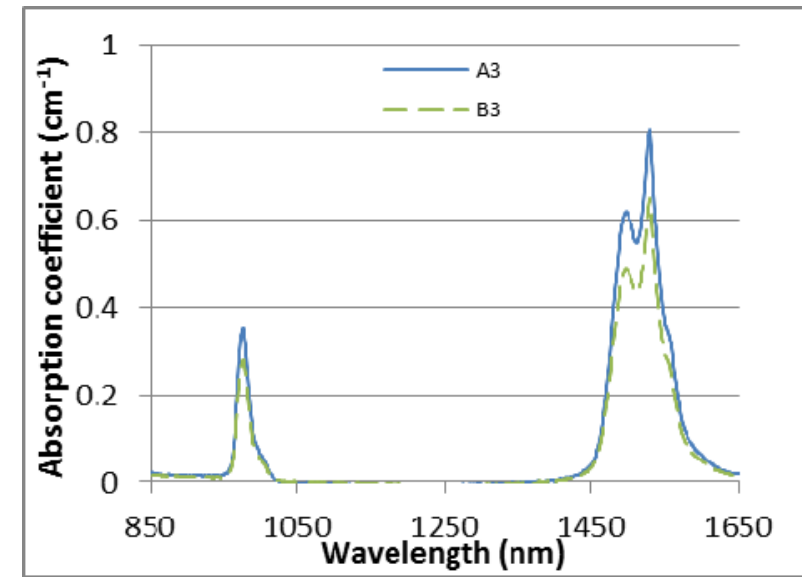

(a)

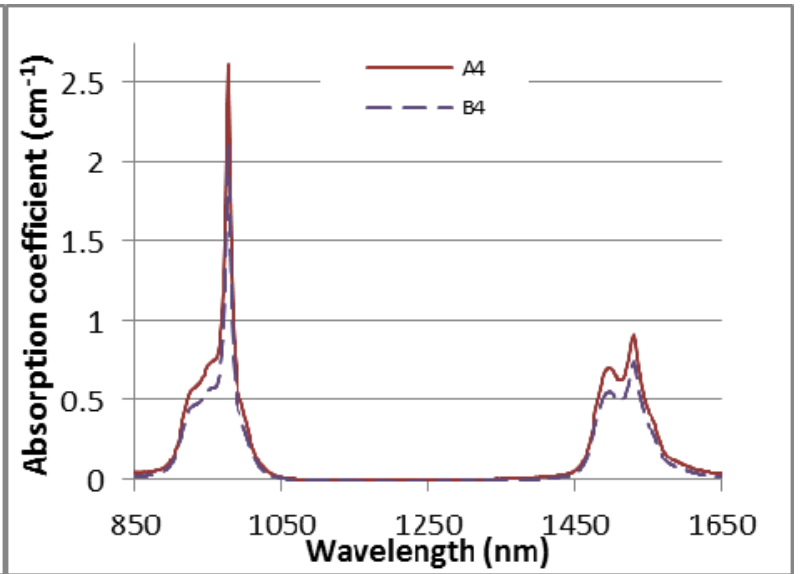

(b)

Fig 1. Absorption coefficients for the (a) singly and (b) co-doped samples studied.

Table 3: Key spectroscopic parameters for the singly and co-doped samples studied.

\begin{tabular}{ccccc}
\hline \hline Sample & $\begin{array}{c}\text { Peak } \alpha_{\mathrm{abs}} \\
@ 0.98 \mu \mathrm{m}\left(\mathrm{cm}^{-1}\right)\end{array}$ & $\begin{array}{c}\text { Peak } \sigma_{\mathrm{em}} @ 1532 \mathrm{~nm} \\
\left(\mathrm{pm}^{2}\right)\end{array}$ & $\begin{array}{c}\text { FWHM } \sigma_{\mathrm{em}} \\
(\mathrm{nm})\end{array}$ & $\begin{array}{c}\tau_{\mathrm{f}} \\
(\mathrm{ms})\end{array}$ \\
\hline A3 & 0.35 & 0.79 & 50.1 & 2.9 \\
$\mathrm{~A} 4$ & 2.62 & 0.81 & 51.8 & 3.0 \\
$\mathrm{~B} 3$ & 0.28 & 0.66 & 49.8 & 3.0 \\
$\mathrm{~B} 4$ & 2.08 & 0.75 & 49.8 & 2.9
\end{tabular}

The recorded fluorescence spectrum for each of the erbium doped samples is shown in Fig. 2. The emission spectra were scaled to be equal to the maximum peak of the emission cross section, which was calculated via a modified McCumber (reciprocity) method [10]. Two assumptions were employed in the calculations, firstly, the zero energy level was approximated to be the mean value between absorption and emission peaks, and secondly, the ratio of the partition functions for the ${ }^{4} \mathrm{I}_{13 / 2}$ and ${ }^{4} \mathrm{I}_{15 / 2}$ levels was set to unity. While the general shape of the emission spectra and calculated emission cross section are similar, the measured spectra appears to have higher values either side of the peak, which indicates that the previous assumptions may not be as suitable for these compositions of tellurite glasses, as they were for the glasses investigated by Miniscalco and Quimby [10]. 


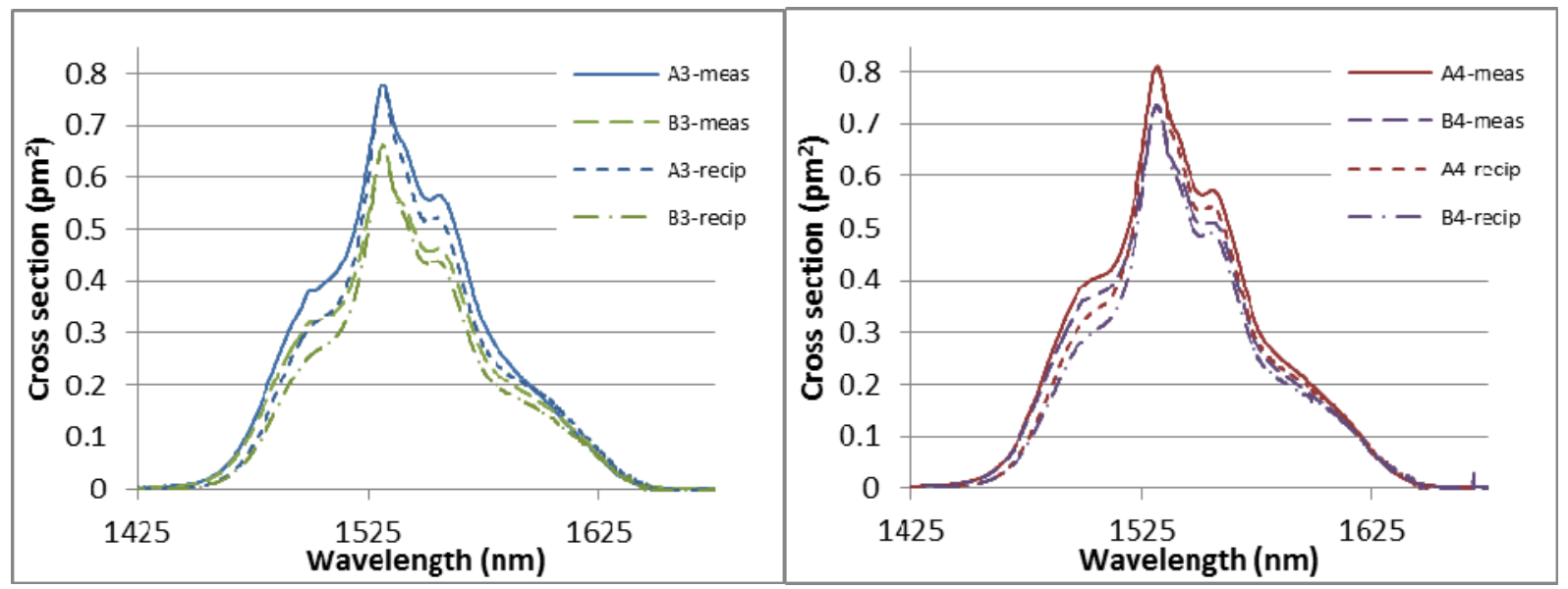

(a)

(b)

Fig 2. Calculated emission cross section (McCumber/reciprocity method, short dash and dash-dot curves) and fluorescence spectrum normalized (solid and long dash curves) to the calculated peak for the (a) singly and (b) co-doped samples.

\subsection{Raman spectra}

Fig. 3 shows a Raman spectrum of a representative glass (A3) from the A-series. As can be clearly seen the spectrum shows the Raman bands corresponding to $\mathrm{TeO}_{2}$ (T1-T3) and $\mathrm{B}_{2} \mathrm{O}_{3}$ (B1-B4) apart from the Boson peak (A) arising due to the material's disorder in the vitreous state, while the composition of the glass has little influence on this peak under normal conditions. The bands T1 and T2 are mainly due to the symmetric and antisymmetric vibrations of the Te-O-Te linkages in $\mathrm{TeO}_{4}$ trigonal bi-pyramids, respectively. Whereas $\mathrm{T} 3$ band is ascribed to the stretching vibrational modes of the $\mathrm{TeO}_{3}$ and $\mathrm{TeO}_{3+1}$ structural units formed by the transformation of $\mathrm{TeO}_{4}$ units due to the addition of the glass modifiers [11]. While the band $\mathrm{B} 1$ is assigned to the vibration of $\mathrm{B}_{2} \mathrm{O}_{5}$ groups, $\mathrm{B} 2$ is due to the vibrations of $\mathrm{BO}_{3}$ and $\mathrm{BO}_{4}$ groups [12]. The band $\mathrm{B} 3$ is due to the presence of $\mathrm{BO}_{2}$ groups and the band $\mathrm{B} 4$ is mainly caused by the stretching vibrations of the $\mathrm{B}-\mathrm{O}^{-}$bonds [13]. Glasses from B-series are expected to show similar Raman spectrum with additional Raman bands around $450 \mathrm{~cm}^{-1}$ due to $\mathrm{GeO}_{2}$ (not shown in Fig.3).

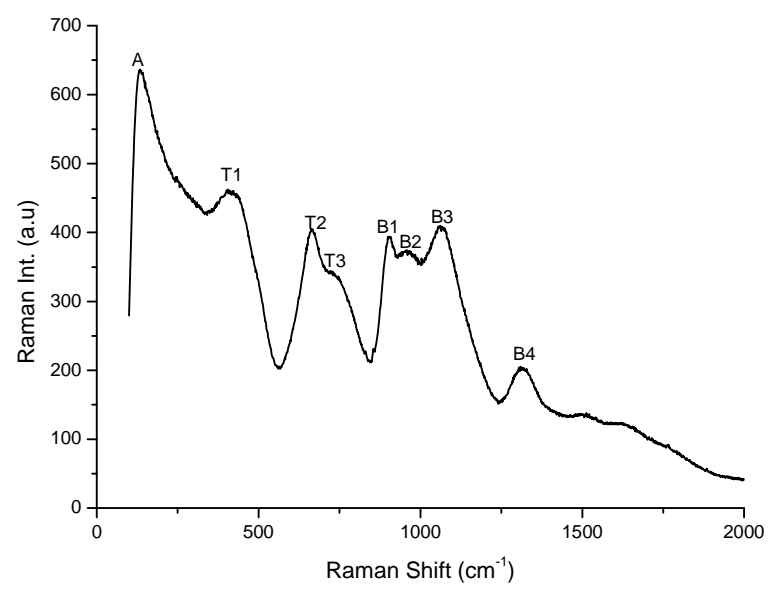

Fig. 3: Raman spectrum of the glass composition A3

\subsection{Gain Measurements}

Measurements of the single-pass small signal gain at discrete wavelengths ( $5 \mathrm{~nm}$ steps from $1525-1600 \mathrm{~nm}$ ) were taken for the Er-doped and Er/Yb co-doped samples. At a maximum pump intensity of $8 \mathrm{kWcm}^{-2}$ and near-normal incidence on the uncoated samples, the highest observed gain at the $1535 \mathrm{~nm}$ emission peak was $2.1 \mathrm{~dB} / \mathrm{cm}$, from the co-doped A4 sample. Significant variation in the gain response was obtained with lateral translation of the sample, consistent with the low optical 
grade of the as cast glass. Each sample was positioned such that the transmitted pump and probe beams were as distortion free as possible and with minimal scattering. The temporal evolution of the gain associated with the $10 \mathrm{~ms}$ pump pulse was captured at each probe wavelength, revealing in some instances a strong spectral dependence for excited state energy transfer processes. Fig. 4 illustrates the measured gain, when the sample was positioned for optimal gain around $1575 \mathrm{~nm}$, for the Er-doped and Er/Yb co-doped samples as a function of the time and at discrete probe wavelengths.

Several key points can be taken from these gain measurements; firstly, for identical pumping conditions the highest gain was achieved with the Er/Yb co-doped A4 glass, though it also absorbed the greatest proportion of the pump power with $40 \%$ of the incident pump transmitted through the sample, 1.9, 1.9, and 1.1 lower than that for the A3, B3, and B4 samples respectively. Secondly, as expected with tellurite glasses the gain bandwidth did extend out around $1600 \mathrm{~nm}$ with a broad shoulder near $1575 \mathrm{~nm}$. Finally, however, in the gain curves presented in Fig. 4 significant excited state absorption (ESA) is evident at several of the probe wavelengths, leading to a highly structured spectral dependence. The exact nature of these ESA channels is yet to be completely confirmed, yet in these glasses the ${ }^{4} \mathrm{I}_{9 / 2}$ multiplet of $\mathrm{Er}^{3+}$ has a peak energy around $\sim 12525 \mathrm{~cm}^{-1}$, corresponding to an exact resonance with two photons with wavelength $1597 \mathrm{~nm}$. At room temperature only a few percent of the excited $\mathrm{Er}^{3+}$ ions would occupy the highest lying ${ }^{4} \mathrm{I}_{13 / 2}$ Stark levels that could be coupled to the ${ }^{4} \mathrm{I}_{9 / 2}$ level by two photons of wavelength $>1570 \mathrm{~nm}$. Whereas a single phonon-emission assisted transition can couple the lower lying ${ }^{4} \mathrm{I}_{13 / 2}$ Stark levels with the ${ }^{4} \mathrm{I}_{9 / 2}$ multiplet over the entire set of probe wavelengths investigated, e.g.:

$$
E r^{3+},{ }_{13 / 2}+h v_{\text {probe }}-h v_{\text {phonon }} \rightarrow E r^{3+},{ }^{4} I_{9 / 2}
$$

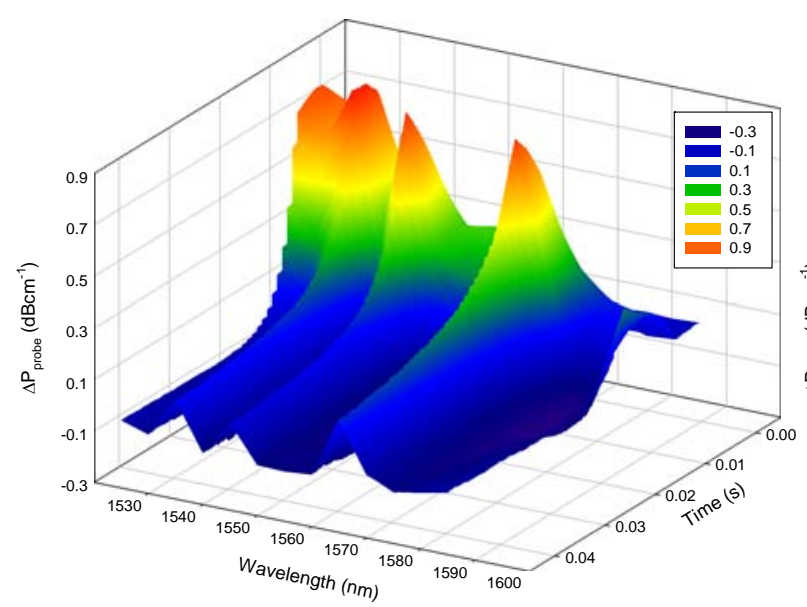

(a)

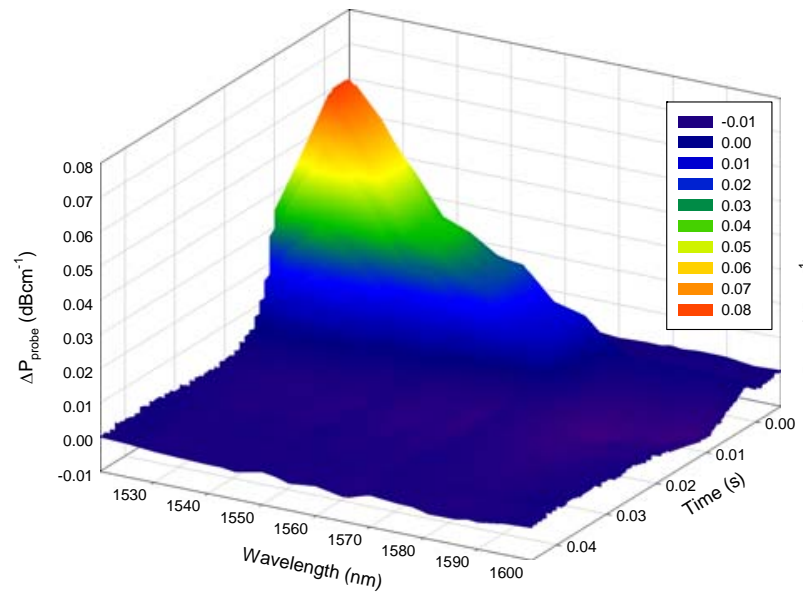

(c)

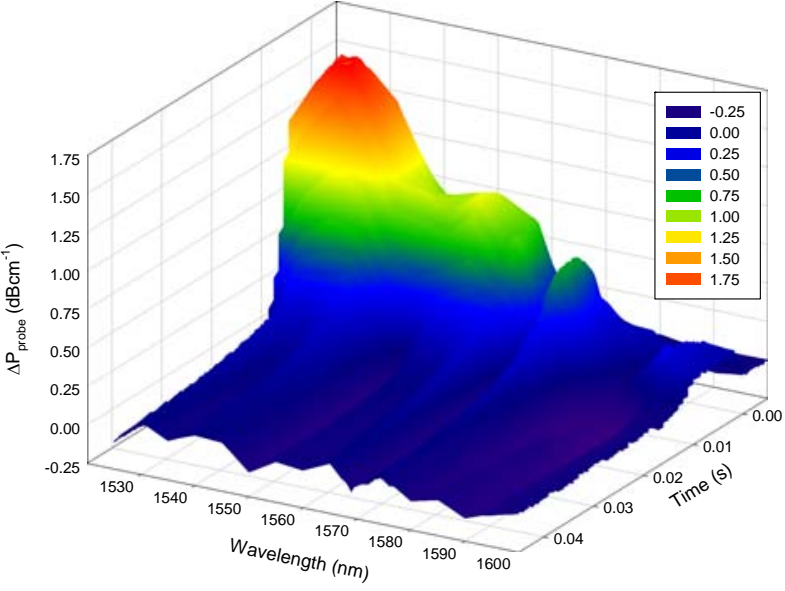

(b)

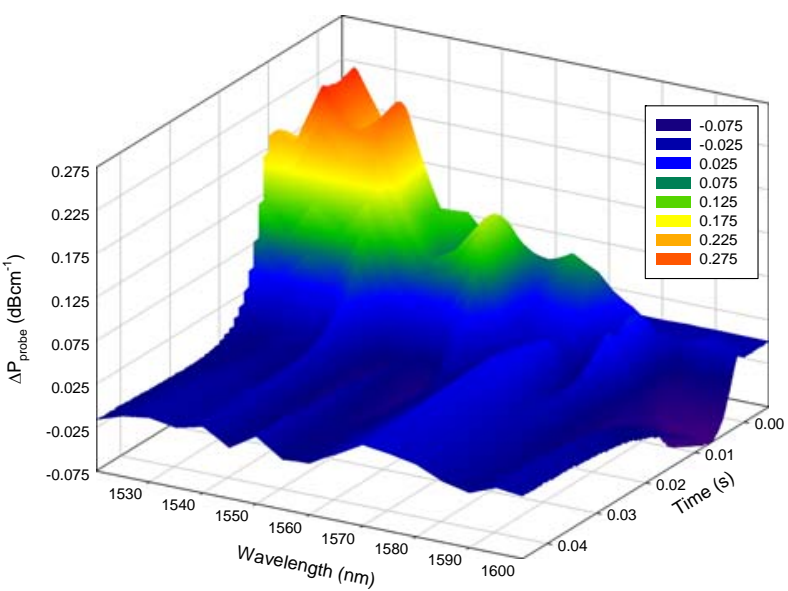

(d)

Fig. 4: Single pass gain (in $\mathrm{dBcm}^{-1}$ ) versus time and probe wavelengths in (a) A3, (b), A4, (c) B3, and (d) B4 glasses 
A clearer representation of the observed ESA effect can be seen in Fig 5, where Fig. 5(a) indicates the respective gain $7.5 \mathrm{~ms}$ into the pump pulse at discrete wavelengths and four different pump intensities, i.e. $3,4.7,6.3$ and $8 \mathrm{kWcm}^{-2}$. The solid curves represent the theoretical gain coefficient in $\mathrm{dBcm}^{-1}$ calculated according to:

$$
G(\lambda)=4.34 \cdot \sigma_{a}(\lambda) \cdot N_{E r}\left(\beta\left(\frac{\sigma_{e}(\lambda)}{\sigma_{a}(\lambda)}+1\right)-1\right)
$$

using the absorption cross section, $\sigma_{\mathrm{a}}(\lambda)$, associated emission cross section, $\sigma_{\mathrm{e}}(\lambda)$, determined using the modified McCumber method described above, the total erbium ion density, $\mathrm{N}_{\mathrm{Er}}$, and the population inversion factor between the $\mathrm{Er}^{3+}$ ${ }^{4} \mathrm{I}_{15 / 2}$ and ${ }^{4} \mathrm{I}_{13 / 2}$ energy levels, $\beta$.

The value for $\beta$ was selected to provide the best fit around the peak emission wavelength, leading to $\beta=0.67,0.72,0.77$, and 0.81 respectively for the solid-line curves with increasing gain coefficient. There is a significant departure from the anticipated gain and the measured gain at the longer wavelengths, supporting the hypothesis that there are additional losses at these longer wavelengths coincident with the potential ESA channels. Further evidence of the ESA effect is shown in Fig. 5 (b) in the temporal response of the probe signal due to the excitation pulse, particularly at the longer wavelengths, where initially the signal increases, but then starts to decrease with continued pumping and accrual of population in the ${ }^{4} \mathrm{I}_{13 / 2}$ energy state.

The very high inversion factors indicated by the good fit to the achieved gain coefficient at the shorter wavelengths in Fig. 5(a), illustrate that the energy transfer from $\mathrm{Yb}^{3+}$ to $\mathrm{Er}^{3+}$ has been very effective. Moreover during the gain measurement no evidence of 1 micron emission confirms that there was very little back transfer of energy from $\mathrm{Er}^{3+}$ to $\mathrm{Yb}^{3+}$.

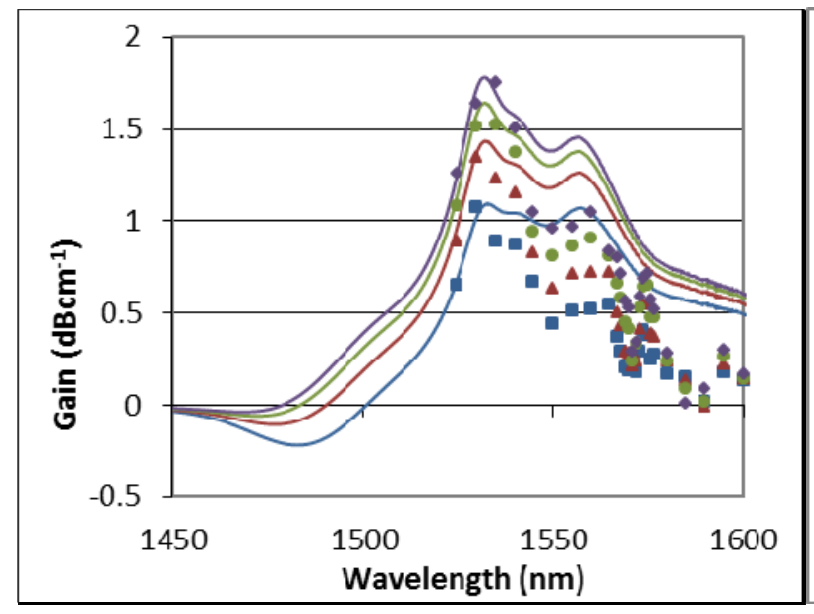

(a)

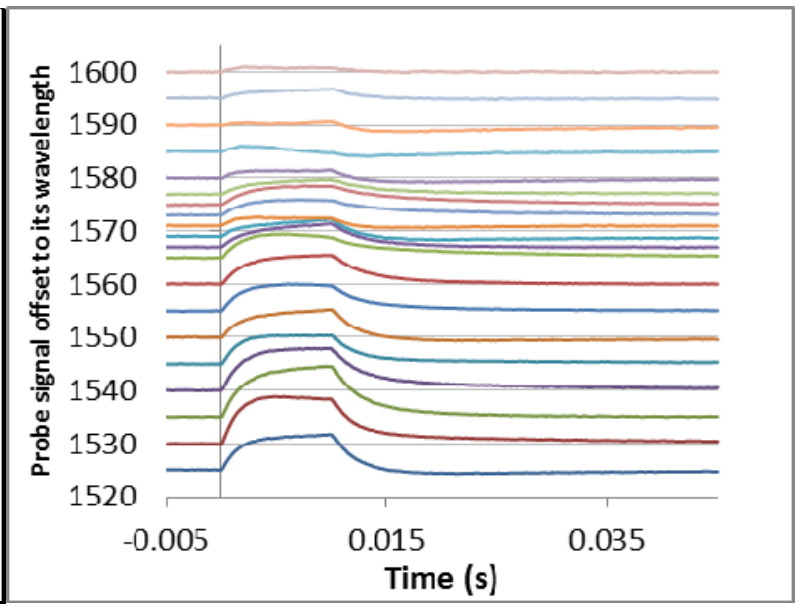

(b)

Fig. 5: (a) Small signal gain measured at $7.5 \mathrm{~ms}$ into the excitation pulse for incident pump intensities of $₫ 3 \mathrm{kWcm}^{-2}$,

$\Delta 4.7 \mathrm{kWcm}^{-2}, 6.3 \mathrm{kWcm}^{-2}$ and $\diamond 8 \mathrm{kWcm}^{-2}$. (b) Probe signal temporal response at different probe wavelengths for the A4 sample and a pump intensity of $8 \mathrm{kWcm}^{-2}$.

\section{CONCLUSION}

We have reported on the spectroscopic properties of $\mathrm{Er}$ and $\mathrm{Er} / \mathrm{Yb}$ doped tellurite glasses with borate (and germanate) additives to tailor the energy transfer to, and lifetime of, the $\mathrm{Er}^{3+}{ }^{4} \mathrm{I}_{13 / 2}$ level when pumping at $980 \mathrm{~nm}$. In addition $\mathrm{MgO}$ was employed as a glass modifier to enhance the broadband nature of the emission spectrum. A high emission cross section of $\sigma_{\mathrm{em}} \sim 0.8 \mathrm{pm}^{2}$ has been derived, along with a measured FWHM bandwidth of $50 \mathrm{~nm}$ and fluorescence lifetime of $3 \mathrm{~ms}$, leading to good $\sigma_{\mathrm{em}} \times \mathrm{FWHM}$ and $\sigma_{\mathrm{em}} \times \tau_{\mathrm{f}}$ figures of merits values. Small signal gain coefficients of $2 \mathrm{dBcm}^{-1} \mathrm{have}$ been measured at the $1532 \mathrm{~nm}$ emission peak, and $0.7 \mathrm{dBcm}^{-1}$ around the $1575 \mathrm{~nm}$ band of interest, coinciding with atmospheric $\mathrm{CO}_{2}$ absorption features. Further work on these glasses is required to optimize their emission lifetime, quantum efficiency, and peak gain at the desired wavelengths, along with their development as suitable materials for planar waveguide power amplifiers. 


\section{ACKNOWLEDGEMENTS}

The authors would like to thank NASA ESTO for the financial support of this effort.

\section{REFERENCES}

[1] J. B. Abshire, H. Riris, G. R. Allan et al., "Pulsed airborne lidar measurements of atmospheric $\mathrm{CO}_{2}$ column absorption," Tellus Series B-Chemical and Physical Meteorology, 62(5), 770-783 (2010).

[2] V. A. G. Rivera, E. F. Chillcce, E. Rodriguez et al., "Planar waveguides by ion exchange in $\mathrm{Er}^{3+}$-doped tellurite glass," Journal of Non-Crystalline Solids, 352(5), 363-367 (2006).

[3] K. Vu, and S. Madden, "Tellurium dioxide Erbium doped planar rib waveguide amplifiers with net gain and $2.8 \mathrm{~dB} / \mathrm{cm}$ internal gain,” Optics Express, 18(18), 19192-19200 (2010).

[4] A. Mori, Y. Ohishi, and S. Sudo, "Erbium-doped tellurite glass fibre laser and amplifier," Electronics Letters, 33(10), 863-864 (1997).

[5] A. Mori, "Tellurite-based fibers and their applications to optical communication networks," Journal of the Ceramic Society of Japan, 116(1358), 1040-1051 (2008).

[6] J. H. Yang, L. L. Hu, S. X. Dai et al., "Fluorescence quenching in $\mathrm{Er}^{3+}$ doped tellurite glass due to the introduction of BO3/2," Journal of Materials Science Letters, 22(8), 575-576 (2003).

[7] D. H. Cho, Y. G. Choi, and K. H. Kim, "Improvement of ${ }^{4} \mathrm{I}_{11 / 2} \rightarrow{ }^{4} \mathrm{I}_{13 / 2}$ transition rate and thermal stabilities in Er ${ }^{3+}$ doped $\mathrm{TeO}_{2}-\mathrm{B}_{2} \mathrm{O}_{3}\left(\mathrm{GeO}_{2}\right)-\mathrm{ZnO}-\mathrm{K}_{2} \mathrm{O}$ glasses," ETRI Journal, 23(4), 151-157 (2001).

[8] C. L. Yu, D. B. He, G. N. Wang et al., "Influence of cationic field strength of modifiers on the $1.53 \mu \mathrm{m}$ spectroscopic properties of $\mathrm{Er}^{3+}$-doped tellurite glasses," Journal of Non-Crystalline Solids, 355(45-47), 2250-2253 (2009).

[9] Y. D. Hu, S. B. Jiang, G. Sorbello et al., "Numerical analyses of the population dynamics and determination of the upconversion coefficients in a new high erbium-doped tellurite glass," Journal of the Optical Society of America BOptical Physics, 18(12), 1928-1934 (2001).

[10] W. J. Miniscalco, and R. S. Quimby, "General procedure for the analysis of $\mathrm{Er}^{3+}$ cross-sections," Optics Letters, 16(4), 258-260 (1991).

[11] G. S. Murugan, and Y. Ohishi, "Structural and physical properties of a novel $\mathrm{TeO}_{2}-\mathrm{BaO}-\mathrm{SrO}-\mathrm{Ta}_{2} \mathrm{O}_{5}$ glass system for photonic device applications," Journal of Non-Crystalline Solids, 351(5), 364-371 (2005).

[12] T. Sekiya, N. Mochida, A. Ohtsuka et al., "Raman-spectra of $\mathrm{BO}_{3 / 2}-\mathrm{TeO}_{2}$ glasses," Journal of Non-Crystalline Solids, 151(3), 222-228 (1992).

[13] D. Maniu, T. Iliescu, I. Ardelean et al., "Raman study on $\mathrm{B}_{2} \mathrm{O}_{3}-\mathrm{CaO}$ glasses," Journal of Molecular Structure, 651, 485-488 (2003). 